
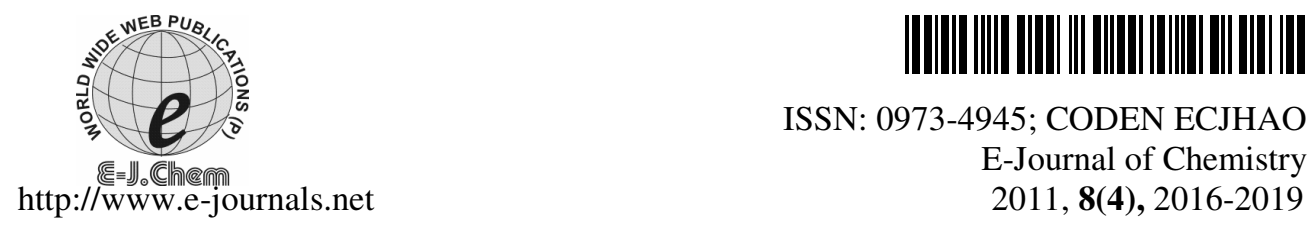

ISSN: 0973-4945; CODEN ECJHAO

E-Journal of Chemistry

2011, 8(4), 2016-2019

\title{
An Improved, Highly Efficient Method for the Synthesis of Bisphenols
}

\author{
L. S. PATIL, V. S. SURYAWANSHI, O. B. PAWAR and N. D. SHINDE* \\ Department of Chemistry \\ Shri Chhatrapati Shivaji College, Omerga - 413 606, India \\ drnds09@ rediffmail.com
}

Received 6 January 2011; Accepted 1 March 2011

\begin{abstract}
An efficient synthesis of bisphenols is described by condensation of substituted phenols with corresponding cyclic ketones in presence of cetyltrimethylammonium chloride and 3-mercaptopropionic acid as a catalyst in extremely high purity and yields.
\end{abstract}

Keywords: Condensation, Bisphenol, Phenol, Cyclic ketone, Cardo monomer

\section{Introduction}

Bisphenols have been attracting great interest because of their importance in synthetic organic chemistry. The condensation products of phenols with cyclic hydroaromatic ketones are known as cardo (a loop) monomers. The monomers containing cardo group are very useful in synthesizing polymer with very specific properties such as enhanced thermal stability together with excellent solubility due to the backbone structure ${ }^{1}$. Bisphenols have been synthesized by condensation of phenols with cyclic ketones or aliphatic ketones in the presence of various catalysts such as boron trifluoride ${ }^{2}$, polyphosphoric acid ${ }^{3,4}$, dry hydrochloric acid 5,6 , acetic $\mathrm{acid}^{7}$, mixture of hydrochloric acid and butylmercaptan and mixture of glacial acetic acid and concentrated sulphuric acid ${ }^{8}$. Although these methods are suitable for synthesis of bisphenols many of these methods are associated with one or more disadvantages such as long reaction times, harsh reaction conditions and unsatisfactory yields, use of halogenated hydrocarbons solvents, tedious workup and multistep purifications. Consequently there is scope for further development easy synthetic procedure applicable to industries with respect to reduce pollution, depletion of our finite environmental resources, optimal use of material and energy, efficient waste management can be recognized as important factor for environmental protection. 
To realize this goal, we describe our successful results that led to an extremely convenient method for the synthesis of bisphenols with appropriate quantity of catalyst. The main advantages of this method are halogenated hydrocarbon solventfree process and simple purification technique in high isolated yields and purity.

\section{Experimental}

Melting point was determined in open glass capillaries and is uncorrected. ${ }^{1} \mathrm{H}$ NMR spectra were recorded at room temperature on a $400 \mathrm{MHz}$ Bruker spectrometer in DMSO-D $\mathrm{D}_{6}$ using TMS as an internal standard. Reactions were monitored by Gas chromatography (Agilent 7890/BP-5). Phenols and ketones were purchased from Merck, India.

Typical experimental procedure for the synthesis of 4,4'-(cyclohexane-1,1diyl)bis(2-methylphenol) (3d)

A $500 \mathrm{~mL}$ four-necked round bottom flask, fitted with an overhead mechanical stirrer, a gas inlet, a dropping funnel, a thermometer and a reflux condenser vented to a scrubber containing aqueous sodium hydroxide scrubber solution was assembled. Flask was charged with $o$-cresol (248 g, 2.3 mole) 3-mercaptopropionic acid (2.7 g) and cetyltrimethylammonium chloride $(0.07 \mathrm{~g})$. The mechanical stirrer was turned on and saturated $o$-cresol with dry $\mathrm{HCl}$ at $38-40{ }^{\circ} \mathrm{C}$ then added cyclohexanone (45 g, 0.46 mole) through dropping funnel within $2 \mathrm{~h}$ at $40-42{ }^{\circ} \mathrm{C}$ and the reaction mass was maintained for $4 \mathrm{~h}$ for completion of reaction. The progress of reaction was monitored by following the disappearance of cyclohexanone using Gas chromatography. After completion of reaction $\mathrm{NaHCO}_{3}(10 \mathrm{~g})$ added slowly and reaction mixture was filtered using Buchner funnel. The wet filter cake was suction dried and washed with $25 \%$ aqueous methanol $(50 \mathrm{~mL} \times 3)$.

\section{Purification}

The crude cake was dissolved in methanol $\left(\approx 375 \mathrm{~mL}\right.$ at $\left.50{ }^{0} \mathrm{C}\right)$ and filtered through

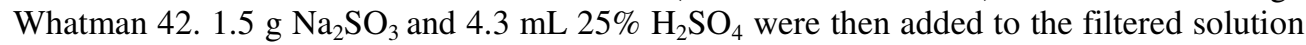
and stirred for $1 \mathrm{~h}$ followed by addition of $3.4 \mathrm{~mL} 46 \%$ caustic lye solution. Then precipitation was carried out at $50{ }^{\circ} \mathrm{C}$ by addition of water and cooled to $40{ }^{\circ} \mathrm{C}$ and filtered using a Buckner funnel. The wet filtered cake was suctioned dried and washed with $25 \%$ aqueous methanol solution and dried in vacuum to afford the pure white crystalline compound in $94 \%$ yield.

\section{4,4'-(Cyclohexane-1,1-diyl)bis(2-methylphenol) (3d)}

White solid; mp. 187-188 ${ }^{\circ} \mathrm{C}$ (Lit. $\left.{ }^{9} \mathrm{mp} .186-187^{0} \mathrm{C}\right)$; IR $\left(\mathrm{KBr}, \mathrm{Cm}^{-1}\right) 1244,1409,1607,2858$, 3063, 3406; ${ }^{1} \mathrm{H}$ NMR (DMSO-D $\left.6,400 \mathrm{MHz}\right) \delta=1.40\left(\mathrm{~s}, 6 \mathrm{H}, \mathrm{CH}_{3}\right), 2.10\left(\mathrm{t}, 6 \mathrm{H}, \mathrm{CH}_{2}\right), 2.50$ $\left(\mathrm{t}, 4 \mathrm{H}, \mathrm{CH}_{2}\right), 6.92(\mathrm{~d}, 2 \mathrm{H}, \mathrm{ArH}), 6.85(\mathrm{dd}, 2 \mathrm{H}, \mathrm{ArH}), 6.63(\mathrm{~d}, 2 \mathrm{H}, \mathrm{ArH}), 9.01(\mathrm{~s}, 2 \mathrm{H}, \mathrm{OH})$; MS m/z: $296\left(\mathrm{M}^{+}\right), 281,279,253,237,239,227$; Anal. calcd. for $\mathrm{C}_{20} \mathrm{H}_{24} \mathrm{O}_{2}: \mathrm{C}$ 81.04, $\mathrm{H}$ 8.16. Found: C 81.24, H 7.98 .

\section{Results and Discussion}

Herein, we report the simple and effective method for the synthesis of bisphenols by condensation of substituted phenols with corresponding cyclic ketones in presence of cetyltrimethylammonium chloride and 3-mercaptopropionic acid (Scheme 1). 


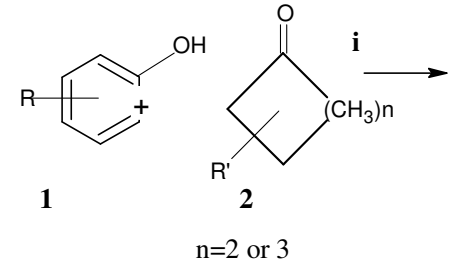

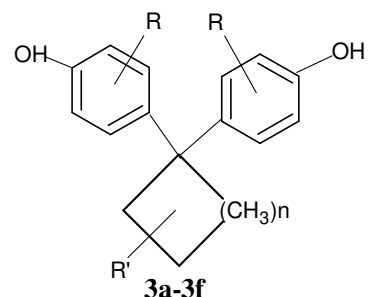

Scheme 1. Reaction Conditions: (i) Cetyltrimethylammonium chloride, 3mercaptopropionic acid, dry $\mathrm{HCl}, 40-45^{\circ} \mathrm{C}, 4 \mathrm{~h}, 60-94 \%$

Use of halogenated hydrocarbon solvents for synthesis of bisphenols involve multiple operation like filtration, purification which resulted into pollution, corrosion of equipment and possibility of iron contamination during acidic material processing and removal of residual halogenated hydrocarbon from products is very difficult. The presence of halogenated hydrocarbon or aromatic solvent in finish bisphenols is not advisable as a view of polymerization. To avoid these problems $\mathrm{NaHCO}_{3}$ is studied in place of halogenated aromatic solvents and it is economical safe method.

Table 1. Synthesis of bisphenols (3a-3f)

\begin{tabular}{|c|c|c|c|c|c|}
\hline Entry & Phenol (1) & Ketone (2) & Product $(3)^{\mathrm{a}}$ & Time, $\mathrm{h}$ & Yield, $\%^{b}$ \\
\hline 1 & Phenol & Cyclohexanone & $3 \mathbf{a}$ & 4 & 91 \\
\hline 2 & Phenol & Cyclopentanone & 3b & 4 & 90 \\
\hline 3 & Phenol & 4-Methylcyclohexanone & $3 c$ & 4 & 89 \\
\hline 4 & $o$-Cresol & Cyclohexanone & 3d & 4 & 94 \\
\hline 5 & $o$-Cresol & 4-Methylcyclohexanone & $3 e$ & 4 & 88 \\
\hline 6 & 2,6-Xylenol & Cyclohexanone & 3f & 8 & 60 \\
\hline
\end{tabular}

${ }^{a}$ All products were characterized by $I R,{ }^{l} H$ NMR and mass spectroscopic data and their melting points compared with literature values. ${ }^{b}$ Isolated yields<smiles>Oc1ccc(C2(c3ccc(O)cc3)CCCCC2)cc1</smiles>

3a<smiles>Cc1cc(C2(c3cc(C)c(O)c(C)c3)CCCCC2)cc(C)c1O</smiles>

3d<smiles>Oc1ccc(C2(c3ccc(O)cc3)CCCC2)cc1</smiles>

3b<smiles>Cc1cc(C2(c3cc(C)c(O)c(C)c3)CCC(C)CC2)cc(C)c1O</smiles><smiles>Cc1cc(C2(c3cc(C)c(O)c(C)c3)CCCCC2)cc(C)c1O</smiles>

3f

Figure 1. Structure of products $(\mathbf{3 a}-\mathbf{3 f})$

This methodology is seems to be more effective, efficient and economical with extremely pure compound with short reaction time and easy workup procedure, no need to handle halogenated hydrocarbon solvents, charcoal and multiple purifications step in the process. 


\section{Conclusion}

In summary, an improved highly efficient method for the preparation of bisphenols by condensation of substituted phenol with corresponding ketones in presence of catalyst with simple purification method was developed in high yield with extremely high purity. The main advantages of this methodology are (1) easy synthetic procedure (2) extremely high purity of product obtained with good yield (3) less Quantity of effluent (4) simple purification (5) short reaction time (6) free of halogenated hydrocarbon solvent and charcoal and (7) commercially economical.

\section{Acknowledgment}

The authors are thankful to Prof. Shingare M S, Department of Chemistry, Dr. Babasaheb Ambedkar Marathwada University, Aurangabad and Dr. Jadhav V Y, Department of Chemistry, Shri Chhatrapati Shivaji College, Omerga for encouragement during the process of carrying out this research work.

\section{References}

1. Vinogradova S V, Salazkin S N, Chelidze G Sh, Slonimskii G L, Askadsky A A, Bichko K A, Komarova L I, Zhuraleva I V and Korshak V V, Plast Massy, 1971, 8, 10.

2. $\quad$ Alpine G Brit, Patent, 941 995, 1963; Chem Abstr., 1964, 60, 1957.

3. Kozlov N S, Klein A G and Sukhodolova V P, Khim Khim Tekhnol., 1973, 2, 63.

4. Kozlov N S, Klein A G and Sukhodolova V P, Dokl Akad Nauk., 1977, 21, 146.

5. $\quad$ Mcgreal N E, Niederl V and Niederl J B, J Am Chem Soc., 1939, 61, 345.

6. Farbenind I G Ger. Patent 467 728, 1927; Chem Abstr., 1929, 23, 1729.

7. Parsania P H, Shah P P, Patel K C and Patel R D, J Macromol Sci Chem., 1985, 22, 1495.

8. Edwin Weber, Cornelia Helbig, Wilhelm Seichter and Mátyás Czugler, J Inclu Phenom Macrocylic Chem., 2002, 43, 239.

9. Garchar H H, Shukla H N and Parsania P H, Indian Acad Sci Chem Sci., 1991, 103, 149-153. 


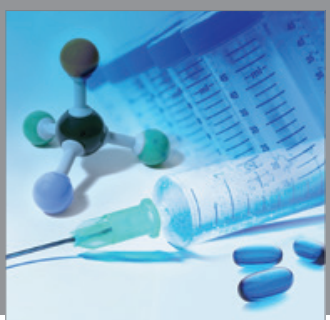

International Journal of

Medicinal Chemistry

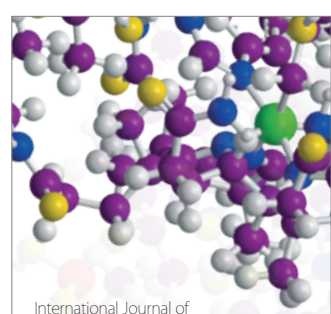

Carbohydrate Chemistry

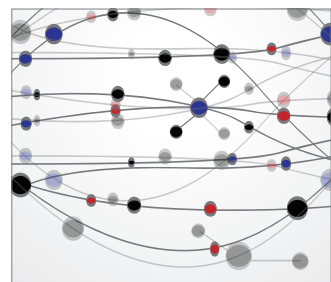

The Scientific World Journal
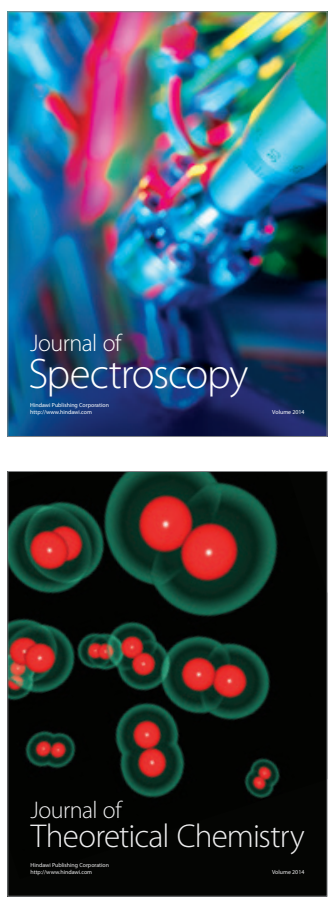
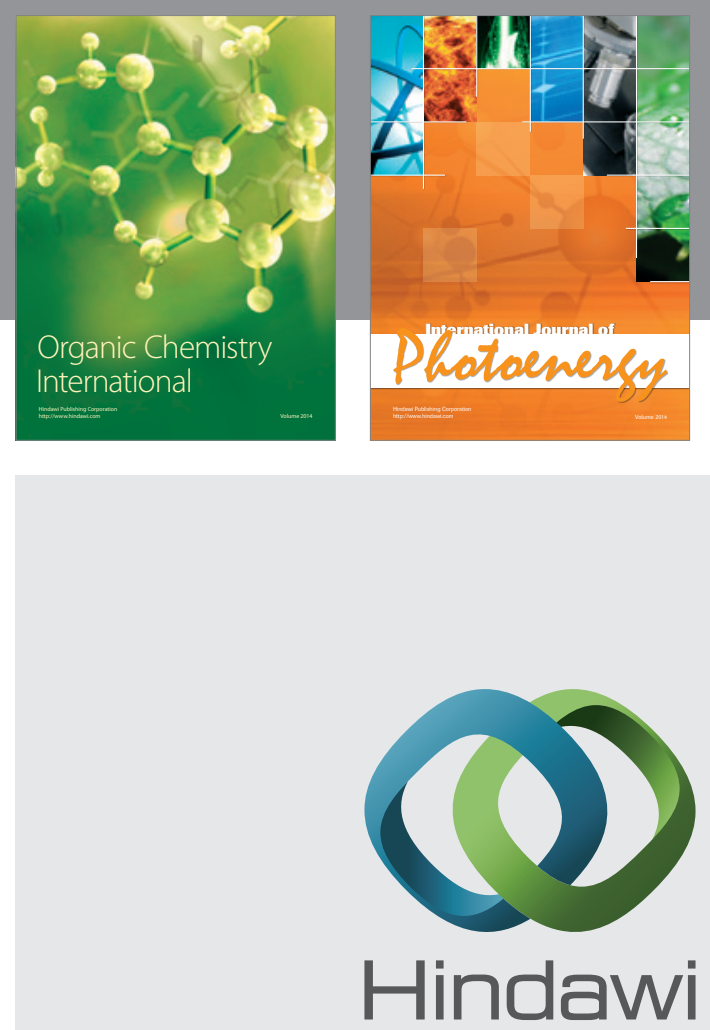

Submit your manuscripts at

http://www.hindawi.com
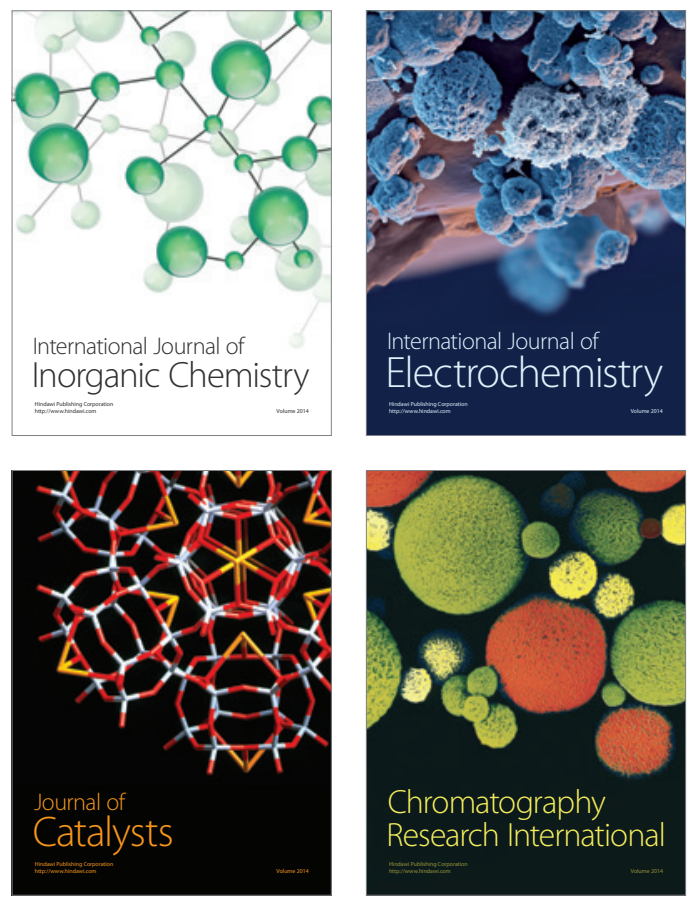
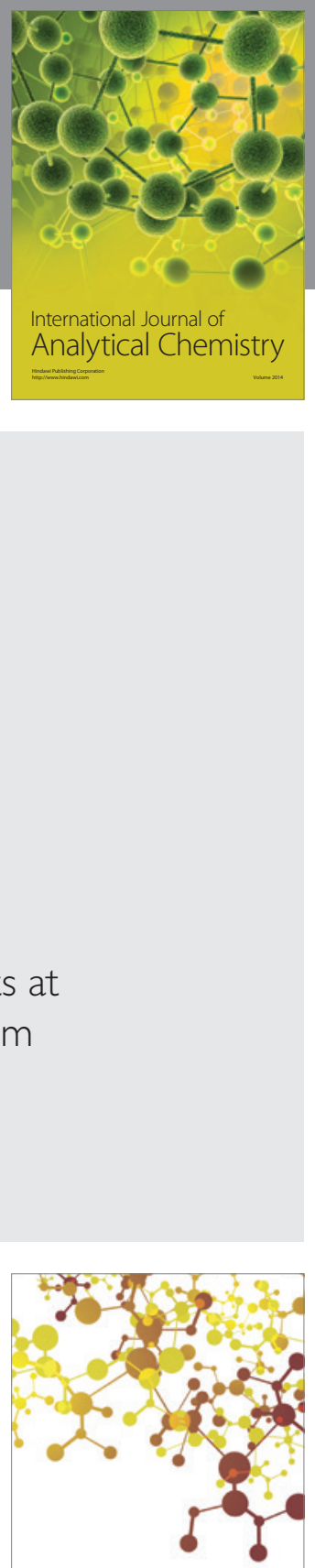

Journal of

Applied Chemistry
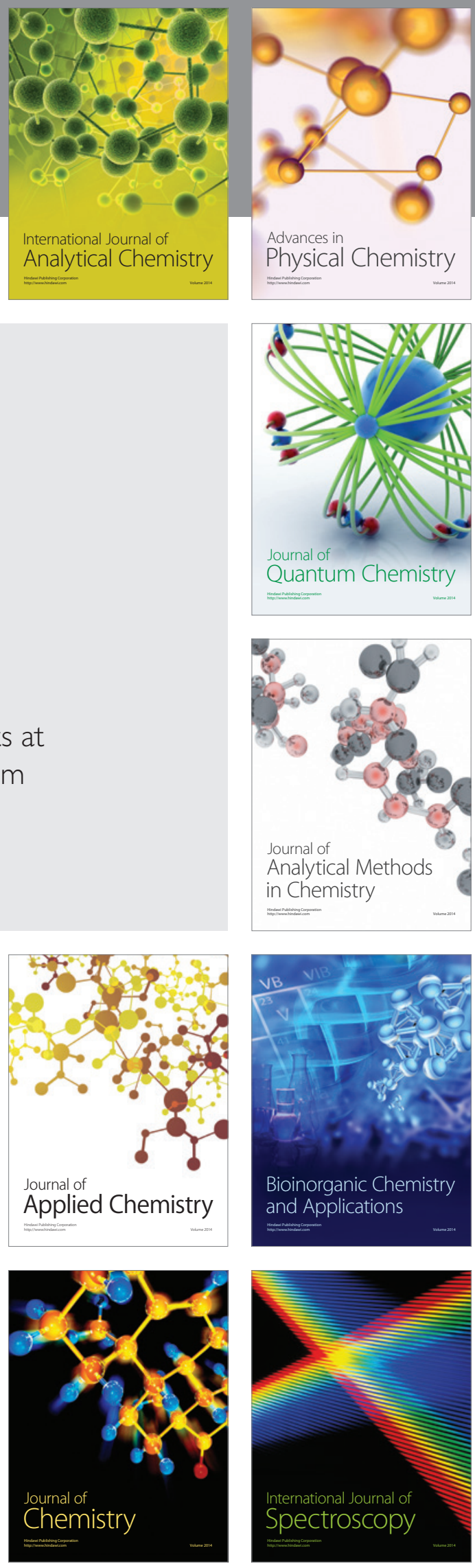